\title{
Electrical and Mechanical Events through Activation of Muscarinic Receptor in the Smooth Muscle of Guinea-pig Vas Deferens
}

\author{
Makoto WaKuI, Yasue Fukushi, and Hachiro InOMATA \\ Department of Applied Physiology, Tohoku University School \\ of Medicine, Sendai, Miyagi, 980 Japan
}

\begin{abstract}
Summary Electrical and mechanical responses of the guinea-pig vas deferens to exogenous acetylcholine (ACh) were observed by means of a single sucrose-gap method. ACh at various concentrations evoked a contraction consisting of two components. The initial component seemed to be independent of a depolarization, while the second one was dependent on it. All $\mathrm{ACh}$ responses were abolished by $\mathrm{Ca}$ removal from the external solution. The results suggest the existence of a pathway by which $\mathrm{ACh}$ even at low concentrations causes a $\mathrm{Ca}$ influx without potential changes.
\end{abstract}

Key Words: guinea-pig vas deferens, acetylcholine, E-C coupling.

Though the role played by endogenous acetylcholine (ACh) in neuromuscular transmission in the guinea-pig vas deferens (SJöSTRAND, 1981) is not clear, it is well known that exogenously applied ACh evokes a contraction (BIRMINGHAM and WiLSON, 1963) and a depolarization (SJöstRAND, 1973) through an activation of muscarinic receptors in this tissue. However, there is not sufficient information at present on the relationship between electrical and mechanical responses to exogenous ACh.

For our experiments, a preparation ( $8 \mathrm{~mm}$ in length, $0.6 \mathrm{~mm}$ in diameter) isolated from longitudinal smooth muscle layer of the guinea-pig vas deferens was used. The preparation was mounted in a single sucrose-gap apparatus which was essentially similar to that described by STÄMPfLI (1954). One end of the preparation was attached to a strain gauge for isometric tension recording with a resting tension of about $0.5 \mathrm{~g}$. A small portion $(2 \mathrm{~mm})$ of the tissue was perfused with a test solution of a constant flow rate. For ACh stimulation, ACh was applied to the tissue for a short period, that is, perfusion of the test solution was stopped for a few seconds to inject $0.025 \mathrm{ml}$ of ACh solution (diluted to re-

Received for publication February 6, 1984

泉井 亮, 福士靖江, 猪又八郎 
(a)
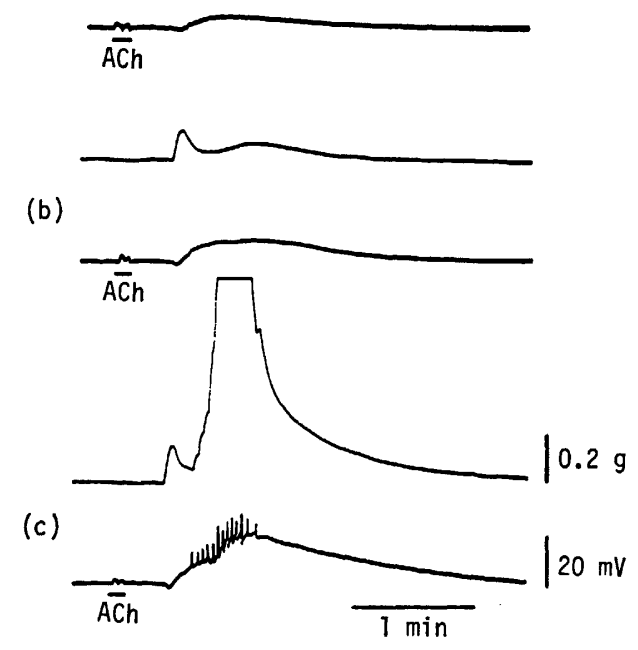

Fig. 1. Electrical and mechanical responses to $\mathrm{ACh}$ at various concentrations in the guineapig vas deferens recorded with a single sucrose-gap method. (a), (b), and (c) were recorded from the same preparation. The upper tracing of each panel shows the changes in tension, and the lower tracing shows the changes in membrane potential. ACh was applied at bars (see text for the way of application). The concentration of $\mathrm{ACh}$ was $10^{-6} \mathrm{M}$ in (a), $10^{-5} \mathrm{M}$ in (b), and $10^{-4} \mathrm{M}$ in (c). Transient downward deflection of potential trace after a force development seems to be an artifact due to some mixture of sucrose with a test solution.

quired concentration with the test solution) into a test solution tube, and then the perfusion was reopened to bring the drug to the tissue. This injection was done far enough from the tissue for full recovery of the tissue and sucrose gap from any damage due to this injecting procedure before the drug reached the tissue. With this short application method, the response to ACh was very reproducible. TTX $\left(10^{-7} \mathrm{M}\right)$ and guanethidine $\left(10^{-7} \mathrm{M}\right)$ were employed throughout the experiments to avoid some responses through the nerve system. As seen in Fig. 1, ACh at low concentrations $\left(10^{-6}-10^{-5} \mathrm{M}\right)$ evoked a depolarization which was not enough to initiate a development of action potentials. ACh at these concentrations produced a contraction consisting of two components. An initial phasic contraction started just before development of the depolarization, and the time to its peak was faster than that of the depolarization. A second contraction, though its onset was unclear, had a time course similar to that of the depolarization. Therefore the membrane depolarization seems to involve only the second contraction. At a high concentration of $\mathrm{ACh}\left(10^{-4} \mathrm{M}\right)$, the magnitude of the depolarization was increased enough to initiate action potentials, and a large contraction developed 


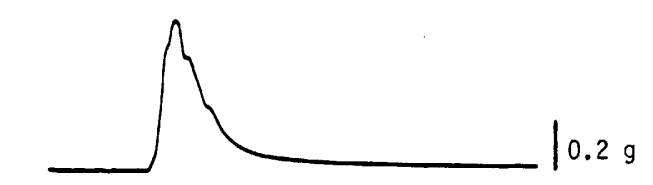

(a)

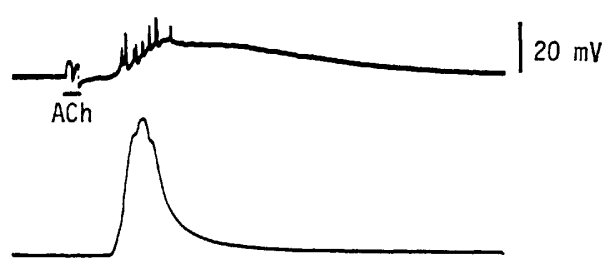

(b)

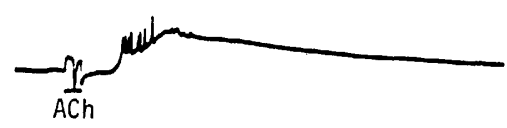

(c)

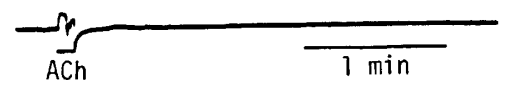

Fig. 2. Effects of removal of external $\mathrm{Ca}$ ions on the responses to $\mathrm{ACh}$ in the guinea-pig vas deferens. (a), (b), and (c) were recorded from the same preparation but in normal solution containing $2.0 \mathrm{mM} \mathrm{CaCl}$ and $1.2 \mathrm{mM} \mathrm{MgCl}_{2}$ (a), $8 \mathrm{~min}$ after exposure to a solution with $6.2 \mathrm{mM} \mathrm{MgCl}(\mathrm{b})$, and $15 \mathrm{~min}$ after exposure to a Ca-free, $0.5 \mathrm{~mm}$ EGTA, and $6.2 \mathrm{mM} \mathrm{MgCl} 2$ containing solution (c). The resting potential was not much affected by the elevation of $\mathrm{MgCl}_{2}$ concentration, but the membrane was depolarized (about $5 \mathrm{mV}$ ) by exposure to the $\mathrm{Ca}$-free solution. The concentration of $\mathrm{ACh}$ was $10^{-3} \mathrm{M}$ throughout this experiment.

synchronously to them. At ACh concentrations greater than $10^{-4} \mathrm{M}$, these components of the contraction overlapped very often owing to a rapid membrane depolarization. All responses to $\mathrm{ACh}$ were abolished by treatment with atropine $\left(10^{-6} \mathrm{M}\right)$.

Another experiment was carried out investigating the effect of Ca-removal from the external solution on the responses to ACh (Fig. 2). Because the concentration of $\mathrm{MgCl}_{2}$ was elevated from 1.2 to $6.2 \mathrm{mM}$ in a Ca-free solution for a membrane stabilization (BÜLBRING and TOMITA, 1970), the responses to ACh in the test solution but containing $6.2 \mathrm{mM} \mathrm{MgCl}_{2}$ were firstly observed. The events induced by $\mathrm{ACh}$ were not affected with only elevation of $\mathrm{MgCl}_{2}$ concentration. When secondarily the solution was changed to the Ca-free one, all responses to $\mathrm{ACh}$ even at a concentration of $10^{-3} \mathrm{M}$ were abolished.

In the smooth muscle cells, the existence of a pathway by which stimulus substances at large concentrations cause a $\mathrm{Ca}$ influx without changes in membrane 
potential has been postulated (BoLTON, 1979). More recently, it has been reported that a contraction could be evoked in association with no potential change by noradrenaline (NA) at concentrations which did not produce action potentials in the arteriolar smooth muscle (HIRST and NeILD, 1980). Furthermore in our previous study, very similar phenomena to those in the present study were observed in response to NA in the guinea-pig vas deferens (WAKUI and INOMATA, 1984). The present observations suggest that $\mathrm{ACh}$ also may induce a $\mathrm{Ca}$ influx without potential changes in addition to voltage dependent $\mathrm{Ca}$ influx even at low concentrations in the guinea-pig vas deferens, though a microelectrode method seems to be required to confirm this view.

\section{REFERENCES}

Birmingham, A. T. and Wilson, A. B. (1963) Preganglionic and postganglionic stimulation of the guinea-pig isolated vas deferens preparation. Br. J. Pharmacol., 21 : 569-580.

Bolton, T. B. (1979) Mechanisms of action of transmitters and other substances on smooth muscle. Physiol. Rev., 59: 606-718.

BülbRing, E. and Tomita, T. (1970) Effects of Ca removal on the smooth muscle of the guineapig taenia coli. J. Physiol. (Lond.), 210: 217-232.

HiRST, G. D. S. and NeILD, T. O. (1980) Evidence for two populations of excitatory receptors for noradrenaline on arteriolar smooth muscle. Nature, 283: 767-768.

SuöSTRAND, N. O. (1973) Effects of acetylcholine and some other smooth muscle stimulants on the electrical and mechanical responses of the guinea-pig vas deferens to nerve stimulation. Acta Physiol. Scand., 89: 1-9.

SJöstRAND, N. O. (1981) Smooth muscle of vas deferens and other organs in the male reproductive tract. In: Smooth Muscle, ed. by Bülbring, E., Brading, A. F., Jones, A. W., and Томіта, T. Edward Arnold, London, Chap. 16, pp. 367-376.

STÄMPFLI, R. (1954) A new method for measuring membrane potentials with external electrodes. Experientia, 10: 508-509.

WaKUI, M. and Inomata, H. (1984) Requirements of external Ca and $\mathrm{Na}$ for the electrical and mechanical responses to noradrenaline in the smooth muscle of guinea-pig vas deferens. Jpn. J. Physiol., 34: 199-203. 